\title{
SOUND-ARRANGEMENTS AND SOUND-SEQUENCES
}

\author{
Yao Shen \\ University of Michigan
}

Effective foreign language teaching requires a knowledge of the significant sounds in the foreign language as well as those in the native language of the students. Such significant sounds ("phonemes") are determined according to rigorous linguistic procedure and can then be presented in tabular form according to the points of articulation and kinds of release. These sounds are often further classified into consonants and vowels, represented as "C" and "V." Each language has its characteristic consonant and vowel arrangements: $\mathrm{CV}, \mathrm{VC}, \mathrm{CVC}, \mathrm{CCV}, \mathrm{VCC}$, etc. For the foreign language teacher, it is essential to know all the significant sounds and all the sound-arrangements in the foreign language as well as those in the students' native language.

In the oral control of a foreign language, a satisfactory production of its significant sounds is imperative. Of no less significance than such production is the mastery of its soundsequences. For language production involves sounds in the stream of speech-not sounds in isolation. Furthermore, in learning a particular foreign language, students of different native languages with different sound-sequences have different learning problems.

\section{I}

Sapir called our attention to the importance of "phonetic patterning," which helps to explain "why people find it difficult to pronounce certain foreign sounds which they possess in their own language." 1 Sapir was referring to the allophonic relations between apparently "similar sounds" in two or more languages. Fries has pointed out that "each language has not only its own set of distinctive sound features; it also has a limited number of characteristic sequences of consonants and vowels which make up the structural pattern of syllables and words." 2 Fries was p. 50 .

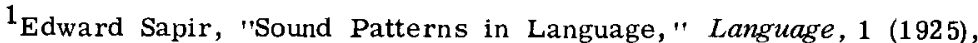

${ }^{2}$ Charles C. Fries, Teaching and Learning English as a Foreign Lanzuage (Ann Arbor, 1945), p. 16. 
referring to the sound-sequence relations between languages. The two words which concern us here are "sequence" and "pattern." By "the structural pattern of the syllables and words," Fries means the consonant and vowel arrangements--sound-arrangements, such as are the abstractly symbolized in formulas like CV, CVC, etc. Similar to the relationship between allophones and phonemes in a language is the relationship between what we may call "sequences" and "arrangements" in the same language.

A "sequence" is an actual, occurrent, specific sequence of specific phonemes: like the English sequences /me/ (met); /spli/ (split);/-et/ (set);/-ispt/ (lisped). An "arrangement" is a formula indicating all similar sequences in terms of " $\mathrm{C}$ " and "V": like the English CV- (in pit, knife, shut); CCCV-(in split, string, squirrel); -VC (in less, pit, splash); -VCCC (in text, grasped, wisps). A "sequence" consists of specific C's and V's; an "arrangement" is a class of sequences which share an identical ordering of their C's and V's.

The transcriptional symbol of a phoneme does not specify its allophones. For example: The formula "English $/ \mathrm{p} /$ " does not specify any of three allophones: aspirated, unaspirated, or unreleased. Similarly, a given $\mathrm{C}-$ and $-\mathrm{V}$ arrangement in a language does not specify its sequences. For example: The formula "CV - in English" does not tell us which consonant is followed by which vowel: / $\mathrm{bi} / ? / \mathrm{se} / ? / \mathrm{na} / ? / \mathrm{pu} /$ ? Yet the production of speech occurs in the specific allophones of phonemes and in the specific sequences of arrangements.

In language description the linguist aims at determining the phonemes and the consonant-and-vowel arrangements. In langauge production the learner must control the specific allophones and the specific sound-sequences in each of the sound-arrangements. In any language there is a limited, exhaustive list of sound-sequences in each permissible sound-arrangement. And speakers of a specific language move with freedom within the restricted sound-sequences of that language. For example: During winter in Ann Arbor, Michigan, U.S.A., there is a natural phenomenon with two co-occurring meteorological features. These features are snow and rain. Native speakers of English call this phenomenon snain but not srain. The linguistic explanation is that / $\mathrm{sn}-/$ occurs in Michigan English and / $\mathrm{sr}-/$ does not occur.

As between languages, there can be similar and different sound-sequences in similar sound-arrangements. In other words, 
two different languages can have similar sound-arrangements, with similar and different sound-sequences in each of the similar sound-arrangements. But a knowledge of the similarity and difference in the descriptive arrangements of either or both languages yields no information about the specific sound-sequences necessary for an oral control of either or both languages. For example: Both English and Thai have C-, CC-, and $\mathrm{CCC}-$. This description tells us nothing about which specific sound-sequences occur as $\mathrm{C}-,, \mathrm{CC}-$, and $\mathrm{CCC}-$.

In the process of learning a foreign language, there are two sets of sound-sequences involved: the one in the foreign language and the one in the native language. In each set, there are four features that characterize each sequence. These four features are the overall arrangement, the constituent phonemes, the specific phoneme sequence, and the position of the sequence in syllable and word structure.

There may be a similarity in arrangement, in phonemes, in sequence, and in sequence position as between two languages. For example: In both Spanish and Tagalog there is the midfront phonetically simple vowel /e/; a slight lowering of the tongue does not cause lexical confusion. In both languages, there is a voiceless fricative / $/$ /; a slight voicing of this phoneme does not cause lexical confusion in either language. There is a voiceless bilabial stop $/ \mathrm{p} /$ with minimal aspiration. The sequences /es/ and / $\mathrm{sp} /$ occur in both languages, and in neither language does / $\mathrm{sp} /$ occur in word initial position. But in both languages, /esp/ does occur in word initial position. As between the two languages, there is similarity in arrangement, in phonemes, in sequence, and in sequence position. They are:

$\begin{array}{lll} & \text { Spanish } & \text { Tagalog } \\ \text { arrangement } & \text { VCC } & \text { VCC } \\ \text { phonemes } & \text { /e,s,p/ } & \text { /e,s,p/ } \\ \text { sequence } & \text { /esp/ } & \text { /esp/ } \\ \text { position } & \text { /esp-/ } & \text { /esp-/ }\end{array}$

On the other hand, there can be dissimilarities between these four features in a foreign language: Michigan English; and those in another language: Mandarin Chinese, Japanese, Tagalog, or Thai. ${ }^{3}$ Such dissimilarities constitute learning difficulties.

3Informants are: for Japanese, Mrs, Hide Inada, a native speaker from Tokyo; for Tagalog, Mrs. Emma Fonancier Bernabe, a native speaker from Manila; for Thai, Miss Prachoom Dabbhasuta, a native speaker from Bangkok. 
And it is the purpose of this article to show some types of sound-arrangement relations and sound-sequence relations illustrating different learning problems and different learning load.

II

Nine types of sound-arrangement relations and sound-sequence relations are given here. The first type is no learning problem, and it is called Type $O$. The other eight types constitute learning problems, and they are numbered from 1 through 8. The presentation of each type begins with a formula to show sound-arrangement relationship and sound-sequence relationship. Examples follow the formula to illustrate the two relationships. The description of the type ends each section. In each type, capital letters within ( ) represent various languages. $C$ means consonant; - means the occurrence of a vowel. Symbols within / / represent various phonemes. $\sim$ means "varies with"; * means non-occurrence. FL means foreign language; NL means native language.

The FL used here is English. The NL is Mandarin Chinese, Japanese, Tagalog, or Thai. The consonant phonemes selected from English are $/ p, t, f, \theta, s, 1, r /$. In Mandarin or Thai, $/ p, t, f, s, 1, r /$ occur; $/ \theta /$ does not occur. In Tagalog, $/ p$, $\mathrm{t}, \mathrm{s}, \mathrm{l}, \mathrm{r} /$ occur; $/ \mathrm{f}, \theta /$ do not occur. In Japanese, $/ \mathrm{p}, \mathrm{t}, \mathrm{s}$, r/ occur; /f, $\theta, 1 /$ do not occur.

$\begin{array}{llllllllllllllll} & \mathrm{p} & \mathrm{t} & \mathrm{f} & \theta & \mathrm{s} & \mathrm{l} & \mathrm{r} / & / \mathrm{p} & \mathrm{t} & \mathrm{s} & \mathrm{r} & 1 & \mathrm{f} & \theta / & \\ \text { English } & \mathrm{x} & \mathrm{x} & \mathrm{x} & \mathrm{x} & \mathrm{x} & \mathrm{x} & \mathrm{x} & \mathrm{x} & \mathrm{x} & \mathrm{x} & \mathrm{x} & \mathrm{x} & \mathrm{x} & \mathrm{x} & \text { English } \\ \text { Mandarin } & \mathrm{x} & \mathrm{x} & \mathrm{x} & \mathrm{x} & \mathrm{x} & \mathrm{x} & \mathrm{x} & \mathrm{x} & \mathrm{x} & \mathrm{x} & \mathrm{x} & \mathrm{x} & & \text { Mandarin } \\ \text { Thai } & \mathrm{x} & \mathrm{x} & \mathrm{x} & \mathrm{x} & \mathrm{x} & \mathrm{x} & \mathrm{x} & \mathrm{x} & \mathrm{x} & \mathrm{x} & \mathrm{x} & \mathrm{x} & \text { Thai } \\ \text { Tagalog } & \mathrm{x} & \mathrm{x} & & \mathrm{x} & \mathrm{x} & \mathrm{x} & \mathrm{x} & \mathrm{x} & \mathrm{x} & \mathrm{x} & \mathrm{x} & & \text { Tagalog } \\ \text { Japanese } & \mathrm{x} & \mathrm{x} & & \mathrm{x} & \mathrm{x} & \mathrm{x} & \mathrm{x} & \mathrm{x} & \mathrm{x} & & & \text { Japanese }\end{array}$

In English, consonants in initial position occur in the following arrangements: $\mathrm{C}_{-}, \mathrm{CC}-$, and $\mathrm{CCC}_{-}$. In Thai, $\mathrm{C}-, \mathrm{CC}-$, and $\mathrm{CCC}-$ also all occur. In Tagalog, $\mathrm{C}$ - and $\mathrm{CC}-$ occur; CCCdoes not occur. In Mandarin and Japanese, C- occurs; CC - and $\mathrm{CCC}$ - do not occur.

$\begin{array}{llll} & \mathrm{C}- & \mathrm{CC}- & \mathrm{CCC}- \\ \text { English } & \mathrm{x} & \mathrm{x} & \mathrm{x} \\ \text { Thai } & \mathrm{x} & \mathrm{x} & \mathrm{x} \\ \text { Tagalog } & \mathrm{x} & \mathrm{x} & \\ \text { Mandarin } & \mathrm{x} & & \\ \text { Japanese } & \mathrm{x} & & \end{array}$


The sound-arrangements selected from English for this study are $\mathrm{CC}-$ and $\mathrm{CCC}-$. The consonant-sequences selected are $/ \mathrm{tr}-/$, $/ \mathrm{fl}-/, / 0 \mathrm{r}-/, / \mathrm{sp}-/, / \mathrm{sf}-/$, and $/ \mathrm{spr}-/$.

Type O. (A) $\quad \mathrm{CC}-/ \mathrm{YZ}-/$

(B) $\mathrm{CC}-/ \mathrm{YZ}-1$

(C) $\mathrm{CC}-/ \mathrm{YZ}-/$

The CC arrangement occurs in English, Tagalog, and Thai. $/ \mathrm{t} /$ and $/ \mathrm{r} /$, and the sequence $/ \mathrm{tr} /$ also occur in all three languages. This sequence occurs in initial position $/ \mathrm{tr}-/$ in all three languages too. Native speakers of Tagalog or Thai have no problem in producing the English $/ \mathrm{tr}-/ \mathrm{tree}$.

$\begin{array}{lll}\text { FL } & \text { English } & \text { CC }-/ \text { tr }-/ \\ \text { NL } & \text { Tagalog } & \text { CC }-/ \text { tr }-/ \\ \text { NL } & \text { Thai } & \text { CC }-/ \text { tr }-/\end{array}$

Type $\mathrm{O}$ may be described as follows: CC-/YZ-/ occurs in (A), (B), or (C). Native speakers of (B) or (C) have no problem in producing $\mathrm{CC}-/ \mathrm{YZ}-/$ in (A). The example is the English / $\mathrm{tr}-/$ for speakers of Tagalog or Thai.

Type 1. (A) $\mathrm{CC}-/ \mathrm{YZ}-/$

(B) $\quad \mathrm{CC}-/-\mathrm{YZ}-1$

$\mathrm{CC}-; / \mathrm{s} /, / \mathrm{p} / ; / \mathrm{sp} /$ occur in English and in Tagalog. /sp-/ occurs in English; / $/$ sp-/ occurs in Tagalog. Native speakers of Tagalog produce the English /sp-/ spear as/-sp. -spear, with a vowel preceding the consonant sequence,

FL English CC - / sp-/

NL Tagalog CC- $/$-sp-/

Type 1 may be described as follows: $\mathrm{CC}-, / \mathrm{Y}, \mathrm{Z} /$, and $/ \mathrm{YZ} /$ occur in (A) and in (B). /YZ -/ occurs in (A);/-YZ-/ occurs in (B). Speakers of (B) substitute $/-\mathrm{YZ}-/$ for $/ \mathrm{YZ}-/$. The example is the English /sp-/ for Tagalog speakers.

Type 1 is the same as Type $O$ in that both the FL and the NL have $\mathrm{CC}-$ and $/ \mathrm{YZ} /$. But in Type $\mathrm{O}$, it is $\mathrm{CC}-/ \mathrm{YZ}-/$; similar phoneme sequence in similar position. In Type 1 , it is 
$\mathrm{CC}-/ \mathrm{YZ}-/$ in the $\mathrm{FL}$ and $\mathrm{CC}-/-\mathrm{YZ}-/$ in the NL: similar phoneme sequence in different positions.

Type 2. a1. (A) $\mathrm{CC}-/ \mathrm{YZ}-/$

(B) $\quad \mathrm{CC}-/ * \mathrm{YZ}-/$

a2. (A) $\mathrm{CC}-/ \mathrm{YZ}-/$

(B) $\quad \mathrm{CC}-/ \mathrm{Y}-\mathrm{Z}-/$

b (A) $\quad \mathrm{CCC}-/ \mathrm{XYZ}-1$

(B) $\quad \mathrm{CCC}-/ \mathrm{X}-\mathrm{YZ}-1$

a1. CC - and /f/, / / occur in English and in Thai. In Eng lish, there is the phoneme sequence $/ \mathrm{fl}-/$. In Thai, initial $/ \mathrm{f} /$ is always followed by a vowel: /f $-/ . / \mathrm{fl}-/$ does not occur in the language. Thai speakers, however, in producing the English /fl-/ flea often produce the sequence /fl-/ flea.

FL English $\quad \mathrm{CC}-/ \mathrm{fl}-/$

NL Thai $\quad \mathrm{CC}-/ * \mathrm{f} 1-/$

a2. $\mathrm{CC}-$ and $/ \mathrm{s} /, / \mathrm{p} /, / \mathrm{f} /$ occur in English and in Thai. In English, initial /s/ may be followed by $/ \mathrm{p} /$ or $/ \mathrm{f} /$ forming $/ \mathrm{sp}-/$ or $/ \mathrm{sf}-/$. In Thai, initial $/ \mathrm{s} /$ is always followed by a vowel: /s-/. /sp-/ or / $/ \mathrm{sf}-/$ do not occur. Speakers of Thai learning English as a FL produce the English /sp-/ spear as /s-p-/ Sapir or the English /sf-/ sphere as /s-f-/ s-phere.

$\begin{array}{lll}\text { FL } & \text { English } & \mathrm{CC}-/ \mathrm{sp}-/ / \mathrm{sf}-/ \\ \mathrm{NL} & \text { Thai } & \mathrm{CC}-/ \mathrm{s}-\mathrm{p}-/ / \mathrm{s}-\mathrm{f}-/\end{array}$

b. CCC - and $/ \mathrm{s} /, / \mathrm{p} /, / \mathrm{r} /$ occur in English and in Thai. In English, /s, p, $r /$ may occur successively in initial position forming $/ \mathrm{spr}-/$. In Thai, initial $/ \mathrm{s} /$ is never followed by another consonant; /p, r / may occur successively forming $/ \mathrm{pr}-/$. Native speakers of Thai produce the English /spr-/ spree as /s-pr-/ s-pree.

FL English CCC $-/$ spr $-/$

NL Thai CCC $-/$ s-pr-/

Type 2 may be described as follows: a. $\mathrm{CC}-$ and $/ \mathrm{Y}, \mathrm{Z} /$ occur in (A) and (B). /YZ-/ occurs in (A); $/ \mathrm{Y}-\mathrm{Z}-/$ occurs in 
(B). a1. Speakers of (B) may produce $/ \mathrm{YZ}-/$ as $/ \mathrm{YZ}-/$. The example is the English $/ \mathrm{fl}-/$ for Thai speakers. a2. Speakers of (B) may produce $/ \mathrm{Y}-\mathrm{Z}-/$ for $/ \mathrm{YZ}-/$. The examples are the English /sp-/ or / $/ \mathrm{sf}-/$ for Thai speakers. b. CCC - and /X, $\mathrm{Y}, \mathrm{Z} /$ occur in (A) and in (B). /XYZ -/ occurs in (A); /X-YZ-/ occurs in (B). Speakers of (B) substitute $/ \mathrm{X}-\mathrm{YZ}-/$ for $/ \mathrm{XYZ}-/$. The example is the English /spr-/ for Thai speakers.

Type $3 . \quad$ a. (A) $\mathrm{CC}-/ \mathrm{YZ}-/$

(B) $\quad \mathrm{CC}-/ \mathrm{XZ}-1$

b. (A) $\quad \mathrm{CC}-/ \mathrm{YZ}-1$

(B) $\quad \mathrm{CC}-/ \mathrm{XZ}-\sim * \mathrm{WZ}-/$

(C) $\mathrm{CC}-/ \mathrm{XZ}-\sim * \mathrm{WZ}-/$

a. CC $-; / \mathrm{p} /, / \mathrm{l} / ; / \mathrm{pl}-/$ occur in Engiish and in Tagalog. $/ \mathrm{f} /$ and $/ \mathrm{fl}-/$ occur in English but not in Tagalog. Native speakers of Tagalog produce the English $/ \mathrm{fl}-/$ flea as $/ \mathrm{pl}-/$ plea.

FL English $\mathrm{CC}-/ \mathrm{fl}-/$

NL Tagalog $\mathrm{CC}-/ \mathrm{pl}-/$

b. $\mathrm{CC}-; / \mathrm{t} /, / \mathrm{r} / ; / \mathrm{tr}-/$ occur in English, Tagalog, and Thai. $/ \theta /$ and $/ \theta \mathrm{r}-/$ occur in English but not in Tagalog or Thai. /s/ occurs in all three languages. /sr-/ does not occur in any of the three languages. Native speakers of Tagalog or Thai produce the English $/ \theta \mathrm{r}-/$ three sometimes as $/ \mathrm{tr}-/$ tree and sometimes as $/ *$ sr $-/ *$ sree.

$\begin{array}{lll}\text { FL } & \text { English } & \text { CC }-/ \theta r-/ \\ \text { NL } & \text { Tagalog } & \text { CC }-/ \text { tr }-\sim * \text { sr }-/ \\ \text { NL } & \text { Thai } & \text { CC }-/ \text { tr }-\sim * \text { Sr }-/\end{array}$

Type 3 may be described as follows: a. $\mathrm{CC}-, / \mathrm{X}, \mathrm{Z} /$, and $/ \mathrm{XZ}-/$ occur in (A) and in (B). $/ \mathrm{Y} /$ and $/ \mathrm{YZ}-/$ occur only in (A). Speakers of (B) substitute $/ \mathrm{XZ}-/$ for $/ \mathrm{YZ}-/$. The example is the English /fl-/ for Tagalog speakers. b. CC-, /W, X, Z/, and $/ \mathrm{XZ}-/$ occur in (A), (B), or (C). /Y/ and /YZ-/ occur only in (A). $/ \mathrm{WZ}-/$ occurs in none of the three languages. Speakers of (B) or (C) substitute $/ \mathrm{XZ}-\sim * \mathrm{WZ}-/$ for $/ \mathrm{YZ}-/$. The example is the English $/ \theta \mathrm{r}-/$ for Tagalog or Thai speakers. 
Type 4.
(A)
$\mathrm{CC}-/ \mathrm{YZ}-1$
(B)
$\mathrm{CC}-/-\mathrm{YX}-/$

$\mathrm{CC}-$ and $/ \mathrm{s} /, / \mathrm{p} /$ occur in English and in Tagalog. / $/$ and $/ \mathrm{sf}-/, / \mathrm{sp}-/$ occur in English. /f/ and /sf-/ do not occur in Tagalog; /sp/ occurs as / $/ \mathrm{sp}-/$. Tagalog speakers produce the English /sf-/ sphere as /-sp-/ -spear.

$\begin{array}{lll}\text { FL } & \text { English } & \text { CC }-/ \text { sf }-/ \\ \text { NL } & \text { Tagalog } & \text { CC }-/-s p-/\end{array}$

Type 4 may be described as follows: $\mathrm{CC}-, / \mathrm{X}, \mathrm{Y} /$, and $/ \mathrm{YX} /$ occur in (A) and (B). /Z/; /YZ-/, /YX-/ occur in (A). $/-\mathrm{YX}-/$ occurs in (B). Speakers of (B) substitute /-YX-/ for /YZ $-/$. The example is the English $/ \mathrm{sf}-/$ for Tagalog speakers.

Type 5. (A)

$\mathrm{CCC}-/ \mathrm{XYZ}-1$

$/-\mathrm{XYZ}-/$

$/ \mathrm{s} /, / \mathrm{p} /, / \mathrm{r} /$ and $/ \mathrm{spr} /$ occur in English and in Tagalog. $\mathrm{CCC}-$ and /spr-/ occur in English; /-spr-/ occurs in Tagalog. Native speakers of Tagalog produce the English /-spr-/-spree as /s-pr-/ -spree.

$\begin{array}{llr}\text { FL } & \text { English } & \mathrm{CCC}-/ \mathrm{XYZ}-/ \\ \mathrm{NL} & \text { Tagalog } & /-\mathrm{XYZ}-/\end{array}$

Type 5 may be described as follows: / $\mathrm{X}, \mathrm{Y}, \mathrm{Z} / \mathrm{and} / \mathrm{XYZ} /$ occur in (A) and (B). CCC - and /XYZ-/ occur in (A); /-XYZ -/ occurs in (B). Speakers of (B) substitute $/-\mathrm{XYZ}-/$ for $/ \mathrm{XYZ}-/$. The example is the English /spr-/ for Tagalog speakers.

Type 5 is different from Type 1. In Type 1, both the FL and the $\mathrm{NL}$ have $\mathrm{CC}$ - and $/ \mathrm{YZ} /$. In the $\mathrm{FL}$, it is $/ \mathrm{YZ}-/$; in the $\mathrm{NL}$, it is $/-\mathrm{YZ}-/$. In Type 5 , the $\mathrm{FL}$ has $\mathrm{CCC}-$; the NL does not have it. Both the FL and the NL have $/ \mathrm{XYZ} /$. In the $\mathrm{FL}$, it is $/ \mathrm{XYZ}-/$; in the NL, it is $/-\mathrm{XYZ}-/$. 
Type 6. a. (A)

$$
\begin{array}{cc}
\mathrm{CC}-\mathrm{YZ}-/ \\
/ \mathrm{Y}-\mathrm{Z}-/
\end{array}
$$

$$
\begin{aligned}
& \mathrm{CCC}- / \mathrm{XYZ}-/ \\
& \text { /X-Y }-\mathrm{Z}-/ \\
& \text { /X-Y }-\mathrm{Z}-/
\end{aligned}
$$

a. Example 1. $\mathrm{C}$ - and $/ \mathrm{f} /, / 1 /, / \mathrm{s} /$ occur in English and in Mandarin Chinese. $\mathrm{CC}-$ and $/ \mathrm{fl}-/, / \mathrm{sf}-/$ occur in English but not in Mandarin. Mandarin speakers produce the English /fl-/ flea as /f-l-/ $f$-lea, and the English /sf-/ sphere as /s-f-/ $s$-phere.

$\begin{array}{llrl}\text { FL } & \text { English } & \mathrm{CC}-/ \mathrm{fl}-/ & / \mathrm{sf}-/ \\ \mathrm{NL} & \text { Mandarin } & / \mathrm{f}-\mathrm{l}-/ & / \mathrm{s}-\mathrm{f}-/\end{array}$

Example 2. $\mathrm{C}-$ and $/ \mathrm{s} / \mathrm{,} / \mathrm{p} / \mathrm{,} / \mathrm{t} / \mathrm{,} / \mathrm{r} /$ occur in English, Mandarin, or Japanese. $\mathrm{CC}-$ and $/ \mathrm{sp}-/, / \mathrm{tr}-/$ occur in English but not in Mandarin or Japanese. Native speakers of Mandarin or Japanese produce the English /sp-/ spear as /s-p-/ Sapir and the English $/ \mathrm{tr}-/$ train as $/ \mathrm{t}-\mathrm{r}-/$ terrain.

$\begin{array}{llr}\text { FL } & \text { English } & \mathrm{CC}-/ \mathrm{sp}-/ / \mathrm{tr}-/ \\ \text { NL } & \text { Mandarin } & / \mathrm{s}-\mathrm{p}-/ / \mathrm{t}-\mathrm{r}-/ \\ \mathrm{NL} & \text { Japanese } & / \mathrm{s}-\mathrm{p}-/ / \mathrm{t}-\mathrm{r}-/\end{array}$

b. C- and $/ \mathrm{s} /, / \mathrm{p} /, / \mathrm{r} /$ occur in English, Mandarin, or Japanese. CCC - and / spr-/ occur in English but not in Mandarin or Japanese. Native speakers of Mandarin or Japanese produce the English /spr-/spree as /s-p-r-/s-p-ree.

$\begin{array}{llr}\text { FL } & \text { English } & \text { CCC }-/ s p r-/ \\ \text { NL } & \text { Mandarin } & / s-p-r-/ \\ \text { NL } & \text { Japanese } & / s-p-r-/\end{array}$

Type 6 may be described as follows: a. C - and /Y, Z/ occur in (A), (B), or (C). CC - and /YZ -/ occur in (A); $/ \mathrm{Y}-\mathrm{Z}-/$ occurs in (B) or (C). Speakers of (B) or (C) substitute $/ \mathrm{Y}-\mathrm{Z}-/$ for $/ \mathrm{YZ}-/$. The examples are the English $/ \mathrm{fl}-/, / \mathrm{sf}-/$ for Mandarin speakers and the English /sp-/, /tr $-/$ for Mandarin or Japanese speakers. b. $\mathrm{C}-$ and $/ \mathrm{X}, \mathrm{Y}, \mathrm{Z} /$ occur in (A), (B), or (C). CCC - and /XYZ -/ occur in (A). /X, Y,Z/ occurs in (B) or (C). Speakers of (B) or (C) substitute $/ \mathrm{X}-\mathrm{Y}-\mathrm{Z}-/$ for $/ \mathrm{XYZ}-/$. The example is the English /spr-/ for Mandarin or Japanese speakers. 
Type 7. a. (A) $\mathrm{CC}-/ \mathrm{YZ}-/$

(B) $\quad / \mathrm{X}-\mathrm{Z}-1$

b. (A) $\mathrm{CC}-/ \mathrm{YZ}-/$

(B) $\quad / \mathrm{X}-\mathrm{Z}-\sim \mathrm{W}-\mathrm{Z}-/$

c. (A) $\mathrm{CC}-/ \mathrm{YZ}-/$

$|\mathrm{Y}-\mathrm{X}-|$

a. C - and $/ \mathrm{s} /, / \mathrm{r} /$ occur in English and in Japanese. CC -; $/ \theta / ; / \theta r-/$ occur in English but not in Japanese. Japanese speakers produce the English $/ \theta r-/$ three as $/ \mathbf{s}-\mathbf{r}-/ \mathrm{s}-\mathrm{ree}$.

$\begin{array}{llr}\text { FL } & \text { English } & \mathrm{CC}-/ \theta \mathrm{r}-/ \\ \mathrm{NL} & \text { Japanese } & / \mathrm{s}-\mathrm{r}-/\end{array}$

b. $\mathrm{C}-$ and $/ \mathrm{s} /, / \mathrm{r} /, / \mathrm{t} /$ occur in English and in Mandarin. $\mathrm{CC}-; / \theta / ; / \theta \mathrm{r}-/$ occur in English but not in Mandarin. Mandarin speakers produce the English $/ \theta r-/$ three sometimes as /s-r-/ $s-r$ ee and sometimes as $/ \mathrm{t}-\mathrm{r}-/ \mathrm{t}$-ree.

$\begin{array}{llr}\text { FL } & \text { English } & \mathrm{CC}-/ \theta \mathrm{r}-/ \\ \mathrm{NL} & \text { Mandarin } & / \mathrm{s}-\mathrm{r}-\sim \mathrm{t}-\mathrm{r}-/\end{array}$

c. C - and $/ \mathrm{s} /, / \mathrm{h} /$ occur in English and in Japanese. CC-; /f/; /sf-/ occur in English but not in Japanese. 4 Japanese speakers produce the English /sf-/ sphere as /s-h-/ s-here.

$\begin{array}{llr}\text { FL } & \text { English } & \text { CC }-/ \text { sf-/ } \\ \text { NL } & \text { Japanese } & / \mathrm{s}-\mathrm{h}-/\end{array}$

Type 7 may be described as follows: a. $C$ - and / X, Z/ occur in (A) and (B). $\mathrm{CC}-, / \mathrm{Y} /$, and $/ \mathrm{YZ}-/ \operatorname{occur}$ in (A). Speakers of (B) substitute $/ \mathrm{X}-\mathrm{Z}-/$ for $/ \mathrm{YZ}-/$. The example is the English $/ \theta \mathrm{r}-/$ for Japanese speakers. b. $\mathrm{C}-$ and $/ \mathrm{X}, \mathrm{W}, \mathrm{Z} /$ occur in (A) and (B). $\mathrm{CC}-, / \mathrm{Y} /$, and $/ \mathrm{YZ}-/$ occur in (A). Speakers of (B) substitute $/ \mathrm{X}-\mathrm{Z}-\sim \mathrm{W}-\mathrm{Z}-/$ for $/ \mathrm{YZ}-/$. The example is the English $/ \theta \mathrm{r}-/$ for Mandarin speakers. c. $\mathrm{C}$ - and $/ \mathrm{Y}, \mathrm{X} / \mathrm{occur}$ in $(\mathrm{A})$ and (B). $\mathrm{CC}-, / \mathrm{Y} /$, and $/ \mathrm{YZ}-/$ occur in (A). Speakers of (B) substitute $/ \mathrm{Y}-\mathrm{X}-/$ for $/ \mathrm{YZ}-/$. The example is the English /sf-/ for Japanese speakers.

$4 / \mathrm{h} /$ occurs as. allophone [f] preceding the high back vowel, but as [h] preceding the other four vowels. 
Type 8. (A) $\mathrm{CC}-/ \mathrm{YZ}-/$

(B) $\quad / \mathrm{W}-\mathrm{X}-/$

$\mathrm{C}-$ and $/ \mathrm{h} /, / \mathrm{r} /$ occur in English and in Japanese. $\mathrm{CC}-$; $/ \mathrm{f} /, / 1 / ; / \mathrm{fl}-/$ occur in English but not in Japanese. Native speakers of Japanese produce the English /fl-/ flea as /h-r-/ $h$-rea.

$\begin{array}{llr}\text { FL } & \text { English } & \mathrm{CC}-/ \mathrm{fl}-/ \\ \mathrm{NL} & \text { Japanese } & / \mathrm{h}-\mathrm{r}-/\end{array}$

Type 8 may be described as follows: $C$ - and $/ W, X /$ occur in (A) and (B). $\quad \mathrm{CC}-; / \mathrm{Y}, \mathrm{Z} / ; / \mathrm{YZ}-/$ occur in (A). Speakers of (B) substitute $/ \mathrm{W}-\mathrm{X}-/$ for $/ \mathrm{YZ}-/$. The example is the English /fl-/ for Japanese speakers.

Examples illustrating all the nine types of sound-arrangement relations and sound-sequence relations are summarized below. The number within ( ) refers to the specific type given above.

\begin{tabular}{|c|c|c|c|c|}
\hline English & Mandarin & Japanese & Tagalog & Thai \\
\hline $\mathrm{CC}-$ & $\mathrm{C}-$ & $\mathrm{C}-$ & $\mathrm{CC}-$ & $\mathrm{CC}-$ \\
\hline $\operatorname{tr}-$ & $\begin{array}{l}t-r- \\
(6 a)\end{array}$ & $\begin{array}{l}t-r- \\
(6 a)\end{array}$ & $\begin{array}{l}\operatorname{tr}- \\
(0)\end{array}$ & $\begin{array}{l}\operatorname{tr}- \\
(0)\end{array}$ \\
\hline $\mathrm{fl}-$ & $\begin{array}{l}f-1- \\
(6 a)\end{array}$ & $\begin{array}{l}h-r- \\
(8)\end{array}$ & $\begin{array}{l}\mathrm{pl}- \\
(3 \mathrm{a})\end{array}$ & $\begin{array}{l}\mathrm{fl}- \\
(2 \mathrm{a} 1)\end{array}$ \\
\hline$\theta r-$ & $\begin{array}{l}s-r-\sim t-r- \\
(7 b)\end{array}$ & $\begin{array}{l}s-r- \\
(7 a)\end{array}$ & $\begin{array}{l}\operatorname{tr}-\sim{ }^{*} \mathrm{sr}- \\
(3 \mathrm{~b})\end{array}$ & $\begin{array}{l}\operatorname{tr}-\sim^{*} \operatorname{sr}- \\
(3 \mathrm{~b})\end{array}$ \\
\hline sp- & $\begin{array}{l}s-p- \\
(6 a)\end{array}$ & $\begin{array}{l}\text { s-p- } \\
(6 a)\end{array}$ & $\begin{array}{l}-\mathrm{sp}- \\
(1)\end{array}$ & $\begin{array}{l}s-p- \\
(2 a 2)\end{array}$ \\
\hline sf- & $\begin{array}{l}s-f- \\
(6 a)\end{array}$ & $\begin{array}{l}s-h- \\
(7 c)\end{array}$ & $\begin{array}{l}-\mathrm{sp}- \\
(4)\end{array}$ & $\begin{array}{l}S-f- \\
(2 \mathrm{a} 2)\end{array}$ \\
\hline $\mathrm{CCC}-$ & $\mathrm{C}-$ & $\mathrm{C}-$ & $\mathrm{CC}-$ & $\mathrm{CCC}-$ \\
\hline spr- & $\begin{array}{l}s-p-r- \\
(6 b)\end{array}$ & $\begin{array}{l}s-p-r- \\
(6 b)\end{array}$ & $\begin{array}{l}- \text { spr }- \\
(5)\end{array}$ & $\begin{array}{l}s-p r- \\
(2 b)\end{array}$ \\
\hline
\end{tabular}

The nine types of sound-sequence relations fall into two groups of sound-arrangement relations. First, the arrangement 
occurs in the FL and in the NL. They are Type O - Type 4. Second, the arrangement in the FL does not occur in the NL. They are Type 5 - Type 8 .

\section{III}

With the above information, we can now analyze the nature of the substitutions used by native speakers of Mandarin Chinese, Japanese, Tagalog, or Thai, when they learn to speak English as a foreign language, so that we may understand their "learning load."

The substitution types given here can be classified into four grades of learning load. The learning load is a function of the number of corrections necessary to attain proper production of the foreign language. The number within ( ) indicates the type of sound-sequence relation described in $I I$. > means "is replaced by."

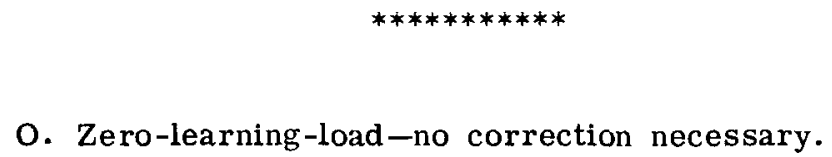

$$
\mathrm{YZ}->\mathrm{YZ}-
$$

a. Similar phoneme sequence in the same position in both the FL and the NL
English
Tagalog
Thai
$\operatorname{tr}-$
$\operatorname{tr}-$
$\operatorname{tr}-$

b. Similar phonemes in the FL and in the NL but absence of the phoneme sequence in the NL.

English

fl-
Thai

$$
* \mathrm{fl} \text { - }
$$


1. Single-learning-load-one correction necessary.

a. Erroneous addition of a vowel to the sequence

1). $\mathrm{YZ}->-\mathrm{YZ}-$

English

Tagalog

sp-

$-\mathrm{sp}$ -

2). $\mathrm{YZ}->\mathrm{Y}-\mathrm{Z}-$

$\begin{array}{llll}\text { English } & \text { Mandarin } & \text { Japanese } & \text { Thai } \\ \text { sp- } & s-p-(6 a) & s-p-(6 a) & s-p-(2 a 2) \\ \text { sf- } & s-f-(6 a) & & s-f-(2 a 2) \\ \text { tr- } & t-r-(6 a) & t-r-(6 a) & \\ f l- & f-1-(6 a) & & \end{array}$

3). $\mathrm{XYZ}->\mathrm{X}-\mathrm{YZ}-$

English Thai

spr - $\quad$ s-pr -

4). $\mathrm{XYZ}->-\mathrm{XYZ}-$

English

Tagalog

spr-

-spr-

b. Erroneous substitution of a consonant phoneme in the sequence.

1). $\mathrm{YZ}->\mathrm{XZ}-$

English

Tagalog

fl-

$\mathrm{pl}$ -

(3a)

2). $\mathrm{YZ}->\mathrm{XZ}-\sim \mathrm{WZ}-$

English

Tagalog

Thai

$\theta r-$

tr $\sim$ *sr -

$\operatorname{tr} \sim \sim *_{\mathrm{sr}}-$ 
2. Double-learning-load-two corrections necessary.

a. Erroneous addition of two vowels to the sequences.

$$
\mathrm{XYZ}->\mathrm{X}-\mathrm{Y}-\mathrm{Z}-
$$

$\begin{array}{lll}\text { English } & \text { Mandarin } & \text { Japanese } \\ \text { spr- } & \mathrm{s}-\mathrm{p}-\mathrm{r}- & \mathrm{s}-\mathrm{p}-\mathrm{r}-\end{array}$

b. Erroneous addition of a vowel to the sequence and erroneous substitution of a consonant in the sequence.

1). $\mathrm{YZ}->-\mathrm{YX}-$

English Tagalog

sf -sp-

2). $\mathrm{YZ}->\mathrm{X}-\mathrm{Z}-$

English

$\theta r-$ Japanese $s-r-$

3). $\mathrm{YZ}->\mathrm{X}-\mathrm{Z}-\sim \mathrm{W}-\mathrm{Z}-$

English

$\theta \mathrm{r}-$ Mandarin $\mathrm{s}-\mathrm{r}-\sim \mathrm{t}-\mathrm{r}-$

4). $\mathrm{YZ}->\mathrm{Y}-\mathrm{X}-$

English Japanese

sf$\mathrm{s}-\mathrm{h}-$

3. Triple-learning-load-three corrections necessary. Erroneous addition of a vowel to the sound sequence and erroneous substitution of two consonants in the sequence.

$$
\mathrm{YZ}->\mathrm{W}-\mathrm{X}-
$$

$\begin{array}{ll}\text { English } & \text { Japanese } \\ \text { fl - } & \text { h-r }-\end{array}$


Every language has a set of significant sounds and soundarrangements. Acquisition of a language requires more than a knowledge of its sounds and its sound-arrangements. The learner must control the sound-sequences. It has been observed here that two languages may have similar arrangements and similar phonemes in similar sequences and in similar positions (Type 0 ). They may have similar arrangements and similar phonemes in similar sequences, but the sequences are in different positions (Type 1). They may have similar arrangements and similar phonemes, but the sequences are different and are in different positions. In one language the phonemes may occur successively. In another language, they may not occur successively (Type 2); they may occur as a different phoneme sequence (Type 3); they may occur as a different phoneme sequence which is always preceded by another phoneme (Type 4). Two languages may have different arrangements and similar phonemes in similar sequences, but the sequences are in different positions (Type 5). They may have different arrangements and similar phonemes, but the phoneme sequences are different and are in different positions. In one language, the phoneme sequence may occur successively. In another language, they may not occur successively (Type 6); they may not occur successively and they occur as different phonemes (Type 7). Two languages may have different arrangements, and different phonemes in different sequences and in different positions (Type 8).

$\begin{array}{llll}\text { arrangement } & \text { phoneme } & \text { sequence } & \text { position } \\ \text { similar } & \text { similar } & \text { similar } & \text { similar (Type O) } \\ \text { similar } & \text { similar } & \text { similar } & \text { different (Type 1) } \\ \text { similar } & \text { similar } & \text { different } & \text { different (Type 2, Type 3, } \\ \text { different } & \text { similar } & \text { similar } & \text { different (Type 5) } \\ \text { different } & \text { similar } & \text { different } & \text { different (Type 6, Type 7) } \\ \text { different } & \text { different } & \text { different } & \text { different (Type 8) }\end{array}$

When two languages have different arrangements, there is always learning difficulty (Type 5 - Type 8). Even when they have similar arrangements, it is not safe to assume that the re are no teaching problems (Type 1 - Type 4). Sound-arrangements do not indicate sound-sequences; sound-sequences indicate sound-arrangements. A speaker does not attain linguistic freedom until he has control of the sound-sequences which occur in the language. 
And every language has its limited, exhaustive, and permissible occurrent sequences.

Effective planning for foreign language teaching calls for a detailed comparison between the sound-arrangements and soundsequences in the FL and in the NL. When a sound-sequence does not occur in the $\mathrm{NL}$, it is possible that native speakers will be capable of producing the sequence. For example: Thai speakers can produce the English $/ \mathrm{fl}-/$.

On the other hand, native speakers might not be able to produce the sound-sequences in the FL which do not occur in their language. In such cases, two kinds of substitutions have been observed:

First, substitution of a sequence that occurs in the FL. This causes confusion. For example: When Mandarin, Japanese, or Thai speakers produce the English /sp-/ as /s-p-/, spear becomes Sapir. When Tagalog or Thai speakers produce the English $/ \theta \mathrm{r}-/$ as $/ \mathrm{tr}-/$, three becomes tree. When Tagalog speakers produce the English $/ \mathrm{fl}-/$ as $/ \mathrm{pl}-/$, flea becomes plea.

Second, substitution of a sequence that does not commonly occur in the FL. This can cause unintelligibility. For example: When Tagalog or Thai speakers produce the English $/ \theta \mathrm{r}-/$ as $/ * s r-/$, three becomes *sree.

This article does not intend to slight the importance of a knowledge of sound-arrangements in linguistic research. It only attempts to show the importance of specific sound-sequences in proper FL learning and teaching. The various kinds of individual learning problems and the different grades of learning load can be more accurately determined by comparing the sound-sequences in the FL with those in the NL. 